\title{
Que professores queremos formar? Uma análise do programa de pós-graduação em Estudos da Linguagem da UEL
}

\author{
What kind of teachers do we want to have? \\ An analysis of the UEL postgraduation program in Language \\ Studies
}

\author{
Aline de Abreu Curunzi Chanan* \\ Núbio Delanne Ferraz Mafra**
}

\begin{abstract}
RESUMO: Os estudos sobre formação de professores têm se ampliado consideravelmente nas últimas décadas e este fato se reflete nos programas de mestrado e doutorado. Este artigo tem como objetivo investigar a formação de professores de línguas portuguesa e estrangeira na pós-graduação em Estudos da Linguagem na Universidade Estadual de Londrina (UEL), no Paraná. Tomamos como referência a área de concentração em linguagem e educação, pois nela encontra-se o objeto a ser estudado. Através da análise dos programas das disciplinas constantes da grade curricular vigente em 2013, suas ementas, referências bibliográficas e do resumo dos grupos de pesquisa que interessam a este trabalho, buscamos compreender 0 impacto da abordagem adotada na formação de professores e pesquisadores. Os dados foram coletados diretamente do site oficial do programa. Esperamos que os dados, as análises e as interpretações contidos neste artigo possam colaborar com a discussão sobre produção de conhecimento na área de formação de professores.
\end{abstract}

PALAVRAS-CHAVE: Formação de professores. Pós-graduação em Estudos da Linguagem. Universidade Estadual de Londrina.

ABSTRACT: Studies about teacher education have been expanded considerably in recent decades, and this fact is reflected in master's and doctoral programs. This article aims to investigate the education of Portuguese and foreign languages teachers in master's and doctoral's degrees in Language Studies at the Universidade Estadual de Londrina, Paraná. We take as reference the language and education area, by the reason that both are our objects of study. Through the programs analysis of the subjects listed in the current curriculum (2013), their summary, references, and the summary of the research groups relevant to this work, we seek to understand the impact of this knowledge approach in teacher education and research. The data were collected directly from the official program website. Hopefully the data, the analysis and the interpretations contained in this article can assist in the discussion of the knowledge production in the area of teacher education.

\footnotetext{
*Mestra em Estudos da Linguagem - UEL. E-mail: aline.curunzi@gmail.com.

${ }^{* *}$ Professor do programa de pós-graduação em Estudos da Linguagem - UEL. E-mail: nubiodelannefmafra@gmail.com.
} 
KEYWORDS: Teacher's education. Postgraduation in Language Studies. Universidade Estadual de Londrina.

\title{
Considerações Iniciais
}

Estudos sobre a formação de professores têm se multiplicado nas últimas décadas: os eventos que tratam deste tema, os profissionais que se propõem a falar sobre isso, as publicações em periódicos especializados impulsionam as discussões a fim de promover melhorias nos mais diversos níveis de ensino e salientam a necessidade de se abordar esse assunto.

Acreditamos que a formação desses profissionais deva ser um processo contínuo, sistemático, organizado, com aprendizagem permanente, durante toda a sua carreira. Como é sabido, não é só a pedagogia que se preocupa com o processo de formação de professores. Cada área, em suas especificidades, busca estudar, discutir a formação de professores, conhecer suas dificuldades, aproximar a teoria da prática, tentando amenizar os problemas cotidianos.

\begin{abstract}
Formar professores para a escola básica é assumir um compromisso social com todos aqueles envolvidos no processo de ensino e aprendizagem e, ainda, com aqueles que serão os alunos dos futuros professores de Língua Portuguesa. Formar professor requer muito mais que passar conteúdo, uma vez que se volta para a formação de uma consciência crítica, que estabeleça um diálogo entre os sujeitos, a fim de despertá-los para a realidade em que estão inseridos (SILVA, 2008, p. 45).
\end{abstract}

Esta necessidade de se por em evidência a formação de professores, também reflete na oferta de disciplinas de pós-graduação.

Como parte central deste artigo, decidimos investigar a formação de professores de línguas portuguesa e estrangeira na pós-graduação em Estudos da Linguagem na Universidade Estadual de Londrina, no Paraná, com a finalidade de compreender o impacto da abordagem adotada na formação de professores e pesquisadores desta instituição. Tomamos como referência a área de concentração em linguagem e educação, pois nela encontra-se o objeto a ser estudado. A partir dos programas das disciplinas, constantes da grade curricular vigente em 2013, suas ementas e referências bibliográficas, 
analisamos as disciplinas e alguns grupos de pesquisa para saber qual o professor que se deseja formar.

A metodologia adotada caracteriza-se pelo enfoque qualitativo com base em pesquisa documental, cuja fonte são os dados coletados diretamente do site oficial do programa. Primeiramente, as referências bibliográficas foram organizadas em planilhas, a fim de se verificar a incidência dos autores e obras. Depois, cada disciplina da área B - Linguagem e Educação - foi analisada separadamente. Acrescentamos à análise comentários pertinentes a respeito de alguns grupos de pesquisa que abordam o tema.

Esperamos que os dados, as análises e as interpretações contidos neste artigo possam colaborar com a discussão sobre produção de conhecimento na área de formação de professores. Ainda, gostaríamos que este trabalho pudesse incentivar as investigações no ambiente escolar, adentrando os muros escolares, a fim de trazer não só o professor para a universidade, mas a universidade para dentro do professor, mudando e aprimorando sua prática. $\mathrm{Na}$ formação docente, segundo Nóvoa (1995), torna-se necessário investir na pessoa do professor e na valorização da experiência pedagógica com o intuito de que esses desenvolvam competências para contextualizar e reelaborar os conhecimentos que ensinam.

Embora o assunto esteja em pauta, atualmente, a formação de professores foi, por muito tempo, deixada de lado. E, quando ao se tratar do tema, interferências políticas e ideológicas fizeram e fazem parte da constituição da identidade de nossos professores. Optamos, primeiramente, em traçar um perfil histórico deste processo para entendermos o professor atual.

\section{Um pouco de história}

Historicamente, podemos pensar que a formação de professores no Brasil é assunto relegado ao segundo plano. Embora as escolas já existissem desde os jesuítas, não havia formação específica aos professores (LUZ, 2010). 
Somente em 1835, estabeleceu-se a primeira escola destinada à formação de professores e, em 1946, o poder público federal regulamentou, por meio da Lei Orgânica do Ensino Normal, os cursos que tinham o objetivo da educação profissional dos professores.

Com a reforma educacional, protagonizada pelos militares em 1971, a formação de professores era contemplada em nível médio, porém, para muitos educadores, essa formação representou um retrocesso uma vez que enfocava mais as práticas pedagógicas do que a formação clássica, predominante até então. Esse tipo de formação, na época, também foi fortalecida em nível superior, por meio dos Cursos de Pedagogia (ORTH et al., 2007).

Segundo Orth e Pauly (2011), na década de 1980, a educação brasileira sofreu a influência de discursos que buscavam democratizar todos os níveis e instâncias educacionais. No espaço acadêmico, a formação docente se defrontava com teorias educacionais construtivas que, em nível educacional, entendiam ser necessário criar-se um movimento de teorização da prática, o que surtiu o efeito segmentário nos cursos de licenciatura, pois os dividia em dois polos: as disciplinas de sala de aula e os estágios supervisionados. Assim, o que deveria unir teoria e prática, serviu apenas para afastar e comprovar que a teoria somente fazia sentido nas academias, na prática pouco funcionava.

Para John Dewey, a separação da teoria e prática na cultura ocidental têm suas origens na Grécia clássica, onde as classes menos privilegiadas eram incumbidas do fornecimento de meios de subsistência pelo trabalho manual, através da prática. Do outro lado, havia os cidadãos que, por fazer parte de uma casta privilegiada socialmente, não precisavam trabalhar e podiam se dedicar às atividades de cunho intelectual, aos estudos das artes e da filosofia, além do lazer, marcando, desta forma, uma clara divisão social. Nas palavras de Diniz Pereira (2011, p. 213):

\footnotetext{
Assim, a filosofia grega, bem como a educação dela decorrente, formalizou a primazia da razão como algo absolutamente separado dos afazeres práticos - o conhecimento como pura contemplação. Por fim, mesmo que a legislação educacional brasileira, no que tange à formação de professores, tenha avançado ao insistir no princípio da
} 
indissociabilidade teoria-prática na preparação desses profissionais e, para tal, determinado um aumento significativo da carga horária teórico-prática nas licenciaturas, isso não garante que as nossas instituições de ensino superior seguirão tal princípio e traduzirão em propostas curriculares tal ideia.

Então, há hierarquização entre teoria e prática associando-se aquilo que é puramente intelectual (a teoria) ao que é superior, enquanto os assuntos relacionados ao material (prática), inferior (DEWEY, 2007).

Defender a hierarquização e dissociabilidade entre teoria e prática na formação docente é uma situação problemática nos dois aspectos: a ênfase na dimensão teórica traz o risco de criarmos conceitos que só funcionem hipoteticamente; se privilegiarmos a prática a formação de educadores pode se limitar ao treinamento de habilidades necessárias ao ensino. Nestes parâmetros, "a formação profissional adequada dos professores não é exclusivamente teórica, mas envolve determinada quantidade de trabalho prático." (DEWEY, 1904).

Schlindwein, Souza e Souza (2012), afirmam que os estudos sobre formação de professores têm-se ampliado consideravelmente em seu espaço de discussão e divulgação nas últimas décadas e relacionam algumas publicações que discutem este assunto: a Revista Brasileira de Pesquisa sobre Formação de Professores, criada em 2009; as séries históricas de no 6 [Formação de Professores no Brasil (1990-1998), organizada por Marli André, em 2002] e no 10 [Formação de Profissionais da Educação, coordenada por Iria Brzezinski, em 2006 organizadas pelo INEP]; os livros publicados a partir dos painéis realizados nos últimos Encontros Nacionais de Didática e Prática de Ensino (ENDIPE, 2008, 2010).

Quanto ao curso de Letras, criado em 1930, podemos verificar a preocupação com a formação do docente:

Com esse olhar para a história dos Cursos de Letras, podemos entender que, do mesmo modo que a implantação do ensino superior no Brasil foi marcada pela função pragmática de formar técnicos profissionais necessários ao novo país, a implantação dos cursos de Letras, como componente de uma Faculdade, nasceu sob o desejo da 
formação para a pesquisa, para a construção do conhecimento, mas sucumbiu ao pragmatismo. Isso assim se mostra como reflexo de um contexto sócio-histórico e ideológico, em que há uma busca pela conquista e pela consolidação de lugares (LUZ, 2010, p. 93).

O ensino de Língua Portuguesa perpassou por diversos momentos: como ferramenta para a dominação, signo de nacionalidade com caráter descritivo e normativo, até a criação de uma língua nacional como expressão da nossa própria cultura e a aceitação dos conceitos da Linguística Aplicada.

Quanto à linguística, Pietri (2005), afirma que ela foi acusada de ser "permissiva" e que causaria a deterioração do ensino do idioma nacional. No entanto, o autor pondera que tal deterioração não se daria em função da desvalorização da tradição gramatical ou das teorias linguísticas, mas sim em função de um projeto político desenvolvimentista, fundamentado na teoria da comunicação, que não era monitorado e nem estava inserido em projetos de formação de professores sob responsabilidade de linguistas.

Ainda hoje, os estudos da linguagem não seguem correntes unânimes em relação ao ensino e aprendizagem de línguas, porém concorda-se na necessidade de um processo de formação eficaz de professores:

\begin{abstract}
Naturalmente não se despreza aqui o conteúdo também ideológico e político de todo fazer científico, mas creio que não seria inadequado dizer que existe hoje certo terreno comum, frequentado pelas correntes dominantes dos estudos da linguagem, que, a partir de preceitos do interacionismo e de contribuições da sociolinguística, produz um desconforto para o preconceito e para a defesa de propostas centradas na norma culta e sua descrição. Não se trata, portanto, de defender a validade universal de uma ciência monolítica sobre todas as coisas - armadilha ideológica já apontada por Paulo Freire -, mas de compreender uma necessidade advinda do percurso histórico do ensino de língua materna em nossas escolas. Em outras palavras, se a ciência nos ajuda a ultrapassar a tradição do preconceito e do descritivismo raso que ainda povoa nosso ensino de língua, é preciso dar a ela a devida importância na formação docente (AGUIAR, 2012, p. 5).
\end{abstract}

Pensar em uma educação de qualidade pressupõe rever o estado do conhecimento de uma determinada área, detectando se as produções 
realizadas são de relevância e se estas atendem às necessidades emanadas da sociedade na qual estão inseridas.

Para Kleiman (2008), há a necessidade de se formar professores com saberes que o possibilitem o efetivo exercício de sua profissão. Para tanto, advoga que os saberes advindos da Linguística Textual e da Literatura, considerados pela Proposta de Diretrizes Curriculares do Curso de Letras (Parecer CNE/CES 492/2001) não dão conta de preparar o futuro professor para o trabalho com os vários tipos de letramentos hoje existentes (BRASIL, 2001).

De acordo com Sánchez Gamboa (1998), foi o aumento da produção científica que ocorreu, especialmente, com a expansão dos programas de mestrado e doutorado no Brasil, nos anos setenta, que levou alguns pesquisadores brasileiros a se preocuparem com o caminho tomado por essa produção.

\section{O centro de ciências humanas em números}

O Centro de Ciências Humanas da Universidade Estadual de Londrina iniciou suas atividades com os cursos de História e Letras. Hoje, o centro é formado por cinco graduações, nove especializações, três mestrados e dois doutorados.

O programa de pós-graduação em Estudos da Linguagem, inserido neste centro de estudos, está dividido em duas áreas de concentração e quatro linhas. A página do PPGEL disponibiliza as disciplinas constantes da grade curricular vigente, bem como os respectivos programas de disciplina. No ano de 2013, a grade do mestrado e doutorado contava com 35 disciplinas optativas distribuídas nas áreas de concentração e linhas. Ambas as linhas, 3 e 4, objetivam estabelecer relações entre aspectos teóricos e a prática docente. 
Figura 1 - Descrição CCLH

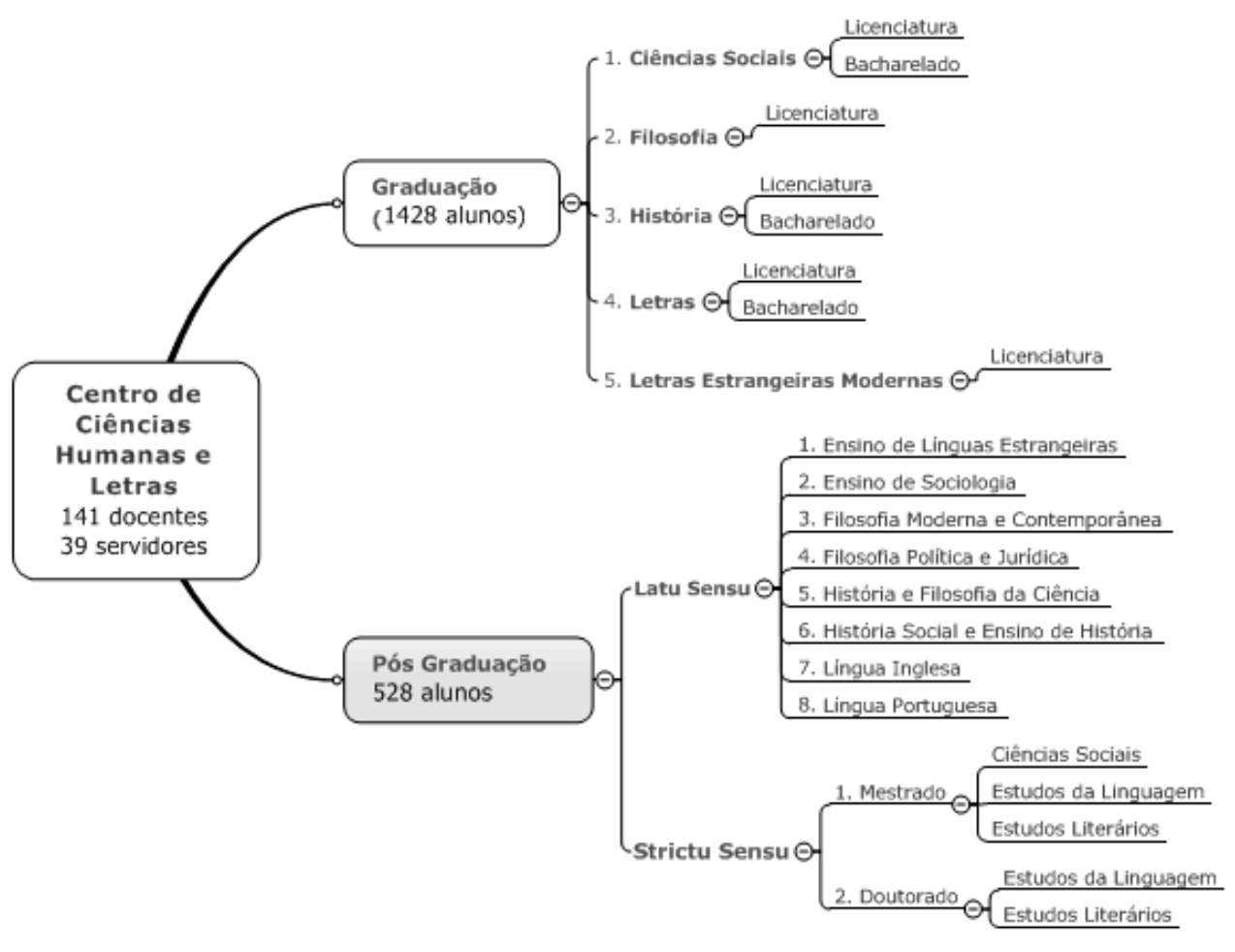

Fonte: elaborado pelos autores.

Pretendemos analisar as disciplinas através de seus programas.

Figura 2 - Áreas de concentração

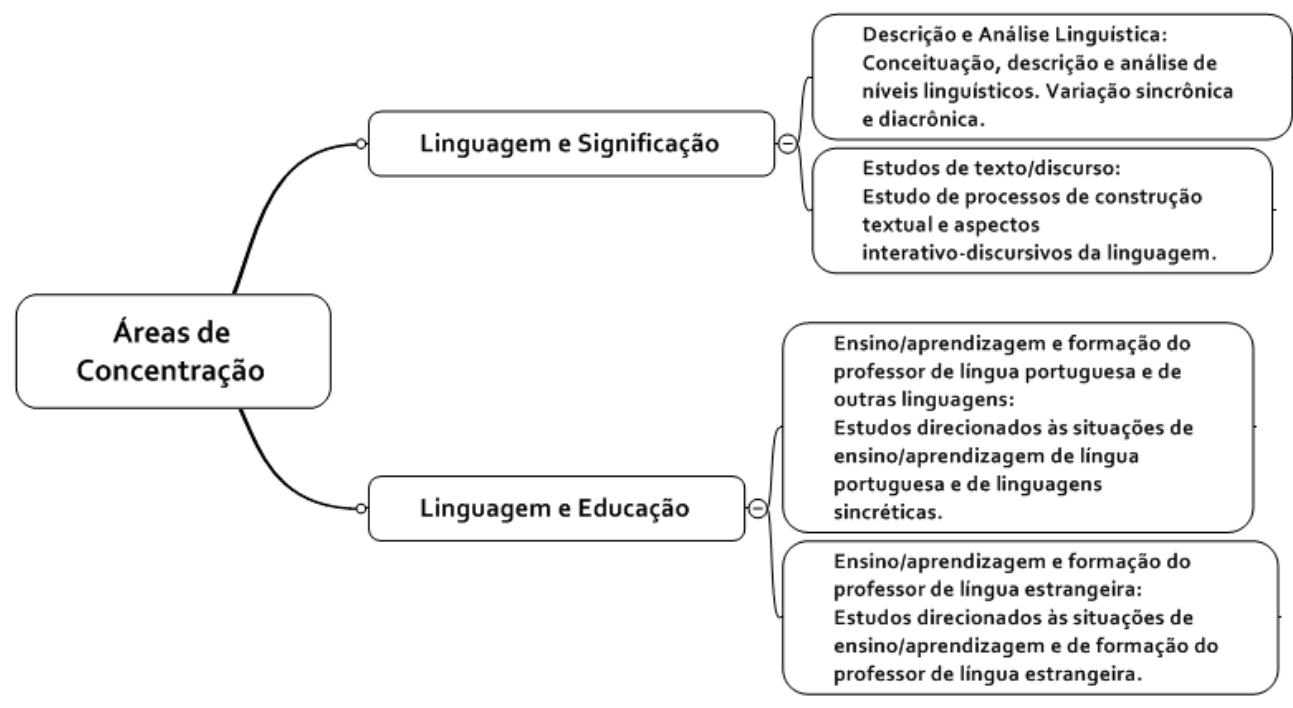

Fonte: elaborado pelos autores. 
Focamos nossas análises na área de concentração B - Linguagem e Educação, nas suas duas linhas de pesquisa. Na linha 3, encontramos nove disciplinas direcionadas ao ensino e aprendizagem de língua portuguesa, das quais somente uma (2LET811 Formação de Professores de Língua Portuguesa) é destinada, explicitamente, a discussão da formação de professores. A gama de disciplinas é variada quanto aos assuntos abordados e relacionados ao ensino de língua portuguesa: semiótica, leitura, escrita, gramática. Iniciamos as análises pelas oito disciplinas da linha 3 que não citam a formação de professores em seu título, mas que estão certamente relacionadas ao ensino e aprendizagem de língua portuguesa.

Figura 3 - Disciplinas linha 3

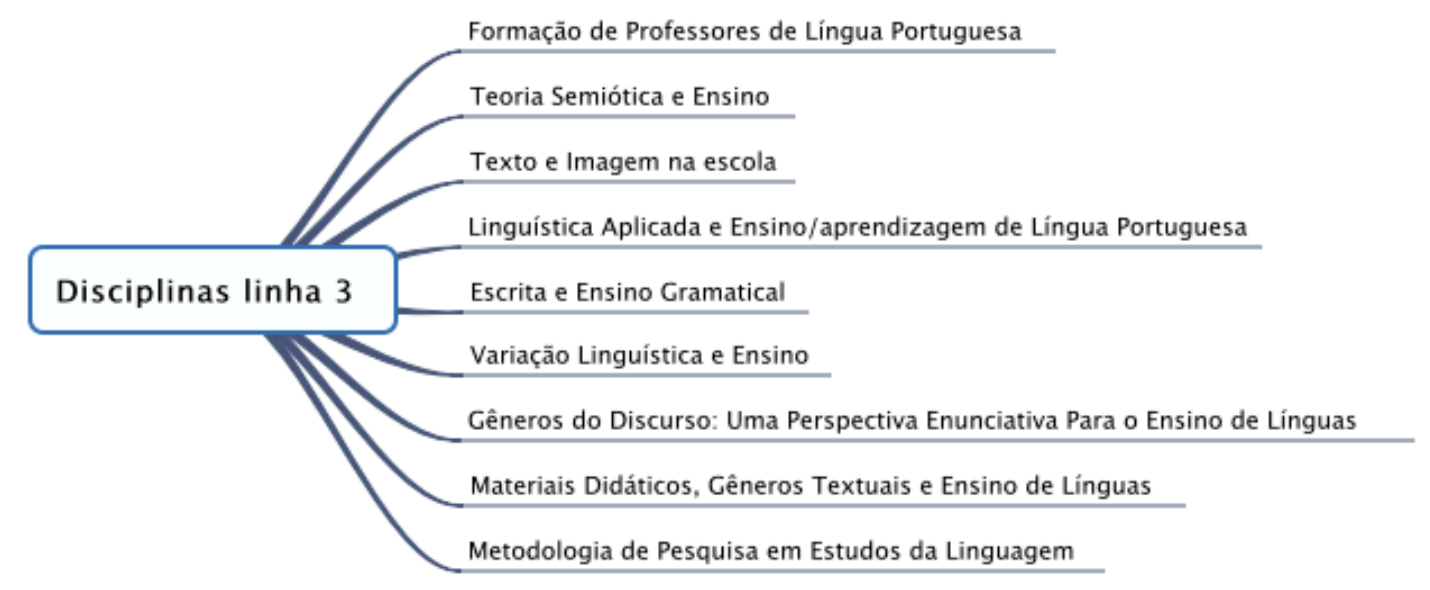

Fonte: elaborado pelos autores.

As disciplinas que abordam a semiótica (2LET405 Teoria Semiótica e Ensino e 2LET777 Texto e Imagem na escola) procuram capacitar o aluno para a prática dos principais elementos desta teoria (pela ótica greimasiana) e motivar sua utilização para o desenvolvimento de estratégias para a análise, visando ao ensino de leitura e produção de textos. Greimas, o autor selecionado pela disciplina, tem a visão mais abrangente do conceito signos, e que consoante a nossa interpretação, tudo pode ser ou se tornar signo.

A semiótica greimasiana é, antes de tudo, uma semiótica linguística, herdeira de Saussure. Segundo esse autor, a linguística faria parte de uma 
semiologia que se ocuparia de todas as linguagens (SAUSSURE, 1967, p. 33). Pela referência bibliográfica sugerida (Silvio de Santana Jr., José Luiz Fiorin, Fernando Hernández, Loredana Limoli, Lúcia Santaella), percebe-se a preocupação em associar a teoria às aplicações no ensino de língua materna.

A Linguística Aplicada como área de investigação científica tem seu lugar em uma disciplina (2LET809 Linguística Aplicada e Ensino/aprendizagem de Língua Portuguesa) que explora desde seu caráter histórico, perpassando pelos documentos oficiais e privilegiando a aplicabilidade nas aulas de língua materna, nas práticas de leitura, produção textual. Nomes como Renilson Menegassi, Angela Kleiman, Luciano Rodrigues Lima, Alaistar Pennycook demonstram a intenção de se aprimorar o debate sobre Linguística Aplicada. Luiz Paulo da Moita Lopes, Alba Maria Perfeito, Lilian Cristina Ritter, Ana Sílvia Aparício, trazem consigo a discussão da escolarização dos saberes para a aula de português.

Além das práticas de leitura e produção textual, o ensino de gramática tem um espaço maior, por haver uma disciplina específica para este tópico (2LET810 Escrita e Ensino Gramatical). Os tópicos apresentam: aspectos históricos; concepções de linguagem e de gramática; o ensino gramatical. As perspectivas de João Wanderley Geraldi, Luiz Carlos Travaglia, Irandé Antunes, Carlos Alberto Faraco, a abordagem através dos gêneros discursivos e dos livros didáticos atribuem aos conteúdos dinamicidade e contemporaneidade à discussão que não mais é ensinar ou não gramática, e sim como e para que ensiná-la. Ainda, Maria Helena de Moura Neves complementa a referência bibliográfica, com "Gramática, análise, teoria, método e ensino", uma publicação muito pertinente a este contexto.

A variação linguística e o ensino é um assunto contemplado pelo programa por uma disciplina (2LET572 Variação Linguística e Ensino). Discutese desde a concepção do termo, o processo identitário, o preconceito linguístico a pesquisa, análise e a diagnose de "erros" no ensino de língua materna.

Ataliba Teixeira de Castilho, Sírio Possenti, João Wanderley Geraldi, Marcos Bagno, Magda Soares, Eugênio Coseriu, entre outros autores de renome 
abrilhantam as referências desta disciplina. Porém, verificamos um caráter mais quantitativo, talvez pela natureza do assunto, na descrição de sua ementa. Dois projetos de pesquisa enriquecem o conhecimento nesta área: "O Atlas Linguístico do Brasil" e a "Variação Linguística na Escola: Propostas didáticas." Percebe-se, claramente, neste último projeto, a intenção de aproximar e instrumentalizar a prática do professor que atua nos diversos níveis de ensino.

Chamou-nos a atenção a incidência da palavra "Gêneros" nos programas, além de ter duas disciplinas para o seu estudo (2LET784 Gêneros do Discurso: Uma Perspectiva Enunciativa Para o Ensino de Línguas e 2 LEM100 Materiais Didáticos, Gêneros Textuais e Ensino de Línguas). A primeira disciplina citada discute, especificamente, o tema sob a ótica do interacionismo sociodiscursivo. Neste contexto, os gêneros são apresentados como instrumentos mediadores para o ensino de línguas.

A teoria dos gêneros começou a surgir para explicar fenômenos que a gramática da frase não explicara. Preocupados em construir uma gramática mais completa, linguistas da década de 70 começaram a conceituar o texto como meio para o ensino da Língua Portuguesa. Os gêneros são formas de funcionamento da língua e linguagem, sendo criados conforme as diferentes esferas da sociedade em que 0 indivíduo circula. São produtos sociais heterogêneos, o que possibilitam infinitas construções durante a comunicação (DOLZ; SCHNEUWLY, 2004)

Além de Bakhtin, Bronckart, Bazerman, Dolz, artigos em eventos e revistas, capítulos de livros de Anna Raquel Machado, Dominique Maingueneau, José Luiz Meures, Desireé Motta-Roth, Elvira Lopes Nascimento, Roxane Rojo e Bernard Schneuwly enriquecem as leituras sobre a prática do professor. Somam-se as estes estudos, o projeto de pesquisa "Atividades de Linguagem e Trabalho Educacional" que visa, a partir dos pressupostos de base do interacionismo sociodiscursivo, pesquisar os três polos do triângulo didático: os saberes, o trabalho do professor e o trabalho dos alunos. 
É proposta uma abordagem de ensino que procura compreender como o professor exerce sua atividade profissional, enfrenta as dificuldades inerentes ao seu contexto e encontra soluções para elas.

Também se materializam na elaboração de material didático dispositivos de ensino a partir dos gêneros textuais e da ideia de agir por meio da linguagem. Relacionamos então, a notável ocorrência dos estudos de gênero nas disciplinas da pós-graduação em questão, com a necessidade de instrumentalizar o pesquisador/professor para que possa levar os alunos a entender a função da língua em seu uso, pelo domínio dos diversos tipos de gênero.

Conforme explica Bazerman (1997, p. 14), os gêneros "são espaços familiares nos quais nós criamos ações comunicativas inteligíveis uns com os outros e são guias que usamos para explorar o não familiar". Portanto os gêneros do discurso são enunciados relativamente estáveis elaborados por diversos campos de utilização da língua, sendo que cada campo elabora seus tipos de enunciados.

Bazerman (2006) explica que os gêneros que atuam em sala de aula devem superar a função de proposições padronizadas, não podemos esvaziar o sentido da atividade em sala de aula, fazendo com que as produções genéricas se tornem meros exercícios formais, cabe aos professores reativar o dinamismo da sala de aula de forma a manter vivos os gêneros que solicitamos nas ações comunicativas da sala de aula. Tomar como base a experiência prévia dos alunos com os gêneros, em situações sociais significativas para eles, pode ser uma proposta.

É de se considerar então, que o objetivo do ensino de gêneros textuais é levar os alunos a produzirem enunciados orais e escritos de modo que os levem a utilizar efetivamente a língua materna. Nesse mesmo sentido, levando em consideração a perspectiva interacionista e sociodiscursiva no ensino de língua materna, Dolz e Schneuwly (2004, p. 49) defendem a ideia do trabalho com a compreensão e produção de gêneros como método de ensino e aprendizagem 
da língua, baseados no princípio de que "aprender uma língua é aprender a comunicar".

Assim, priorizam o desenvolvimento do funcionamento comunicativo dos alunos, que é, em primeiro lugar, prepará-los para dominar a língua em situações variadas, fornecendo-lhes instrumentos eficazes; desenvolver nos alunos uma relação com o comportamento discursivo consciente e voluntário, favorecendo estratégias de autorregulação; ajudá-los a construir uma representação das atividades de escrita e de fala em situações complexas, como produto de um trabalho e de uma lenta elaboração.

Ainda, os trabalhos trazem consigo um cunho prático de ensino de gêneros, estratégias para aprendizado, experiências de sala de aula e reflexão sobre o assunto, que nos fazem perceber a tentativa de aproximação e entendimento da teoria para a inserção dela nos procedimentos escolares e o uso efetivo em salas de aula.

No PPGEL há uma discussão de fundo na questão de gêneros, relacionada aos aspectos discursivos versus textuais. Um debate de tamanha importância que repercute em uma questão ainda maior, de caráter nacional. 0 objetivo de estudo da língua portuguesa muda, não só a nomenclatura, mas a função:

Dessa forma, ensinar leitura e compreensão oral é ensinar a entender discursos, gêneros, enunciados; é ensinar a perceber como os interlocutores usam a língua/linguagem em diversos contextos; comparativamente, ensinar a produção oral e escrita é ensinar a produzir discursos, gêneros, enunciados; é ensinar a usar ("manipular") a língua/linguagem em outros tantos contextos. Isso faz, hoje em dia, parte da orientação para o ensino. É nas ideias de Bakhtin sobre o uso social da palavra que os documentos oficiais encontram base teórica para sugerir essa mudança; é nisso que se embasa o ensino de gêneros (TÁPIAS-OLIVEIRA, 2010, p. 267)

A maior incidência de Bakhtin, Bakhtin e Volochinov e a obra de Dolz, apontam para uma base epistemológica que considera a língua um artefato social. Nesse sentido, utilizar a língua, para qualquer atividade, não é retirá-la 
de dicionários e gramáticas, mas da interação entre as pessoas, é assumir uma voz social. Assim como Bronckart e Bazerman, a ênfase das pesquisas recai no estudo das relações entre linguagem e atividade na perspectiva das interações professor/aluno em processos de ensino e aprendizagem.

Na língua estrangeira, o projeto de pesquisa: "Linguagem e sociedade: possibilidades de participação social de grupos socialmente vulneráveis por meio da língua inglesa" afirma que os gêneros representariam o artefato social de produção, validade, disseminação, cristalização e transformação de conhecimentos em diferentes áreas. Dessa forma, o trabalho com gêneros pode ser uma alternativa no ensino de línguas como instrumento de participação social em intervenções educacionais.

Entendemos que o ensino e aprendizagem nestas disciplinas incorporam o conceito de Bakhtin, na medida em que consideram a língua como objeto social, o homem concebido como social e historicamente situado (mas não deixa de ser também cognitivo, porque ele é epistêmico, tem faculdades cognitivas; a consideração é que o desenvolvimento cognitivo é historicamente situado); e prevalência da concepção da teoria histórico-cultural.

Considerando os dados apresentados até agora e as escolhas das referências, pensamos qual perfil de docente é buscado: não mais o detentor do saber, mas aquele que faça das suas aulas um meio para que seus alunos possam pensar, refletir, e serem verdadeiros sujeitos construtores de conhecimento, capazes de interagir com os seus pares. Melhor se esta prática pedagógica reflexiva se iniciasse na graduação do professor, para que fosse levada com competência e seriedade às séries iniciais da Educação.

Se o professor for preparado científica, técnica, tecnológica, pedagógica, cultural e humanamente, será capaz de participar ativamente do projeto educativo da escola em que exerce a docência, envolvendo-se com a Instituição no seu todo, sentindo-se parte integrante da mesma, a fim de transformar seus alunos em cidadãos críticos, capazes de exercitar a cidadania em sua plenitude. Mas, para isso, precisa ser preparado em sua formação inicial. Há de ser feito um trabalho que busque a conscientização desse futuro professor da escola básica (SILVA, 2008, p. 131). 
Abordando especificamente a formação de professores de língua portuguesa, a disciplina que tem este nome, objetiva levantar as principais tendências dos estudos de currículo no Brasil; abordar a produção científica sobre a formação de professores; discutir questões atuais para esta formação em níveis inicial e continuada; e o currículo no curso de Letras. Para tanto, a referência bibliográfica indica José Luiz Fiorin, João Wanderley Geraldi, Marisa Lajolo, Antonio Nóvoa, Magda Soares, Angela Kleiman, Maurice Tardif. Ainda, os debates são enriquecidos por teses e dissertações que abordam o assunto sob a luz da atualidade, trazendo questões, talvez nem tanto atuais, muitas vezes com soluções apontadas, mas que na escola, na sala de aula, no cotidiano do professor, são de difícil resolução. Pontos importantes como os saberes e a identidade do professor e a relação entre a teoria e a prática, são discutidos amplamente e reaparecem nas vozes dos textos.

Além da disciplina, o grupo de pesquisa FELIP: Formação e ensino de língua portuguesa está vinculado à linha de pesquisa Ensino/Aprendizagem e Formação do Professor de Língua Portuguesa e de Outras Linguagens, que contempla o Curso de Letras (Licenciatura em Língua Portuguesa e Respectivas Literaturas), a Especialização em Língua Portuguesa e o PPGEL - Programa de Pós-Graduação em Estudos da Linguagem.

Apesar de apenas uma disciplina do PPGEL ser especificamente sobre formação de professores existem grupos de pesquisa sobre variados temas acerca deste assunto. Acreditamos ser interessante que outras disciplinas com o intuito de abordar a formação do professor de língua portuguesa fossem propostas. Também, salientamos ser relevante a aproximação das disciplinas com o contexto escolar, através de relatos de experiência, do PIBID, dos estagiários de letras, de trabalhos práticos do $\mathrm{PDE}$, das semanas pedagógicas, já que grande parte dos professores em exercício nas escolas de ensino fundamental e médio salienta que existe muita distância entre teoria e prática. 
Figura 4 - Grupos de pesquisa

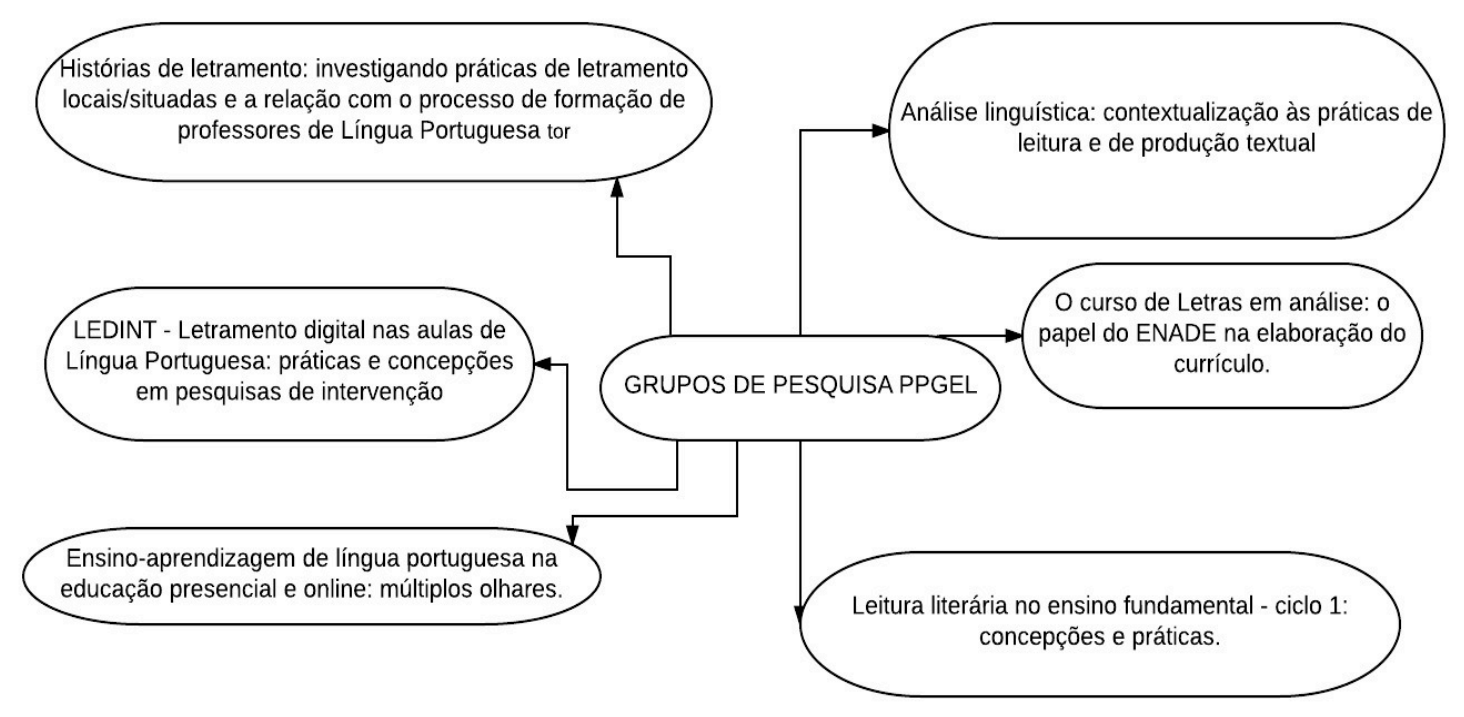

Fonte: elaborado pelos autores.

$\mathrm{Na}$ linha 4, ensino/aprendizagem e formação do professor de língua estrangeira, são sete disciplinas que se destinam a discutir o ensinar e aprender a língua estrangeira.

Figura 5 - Disciplinas linha 4

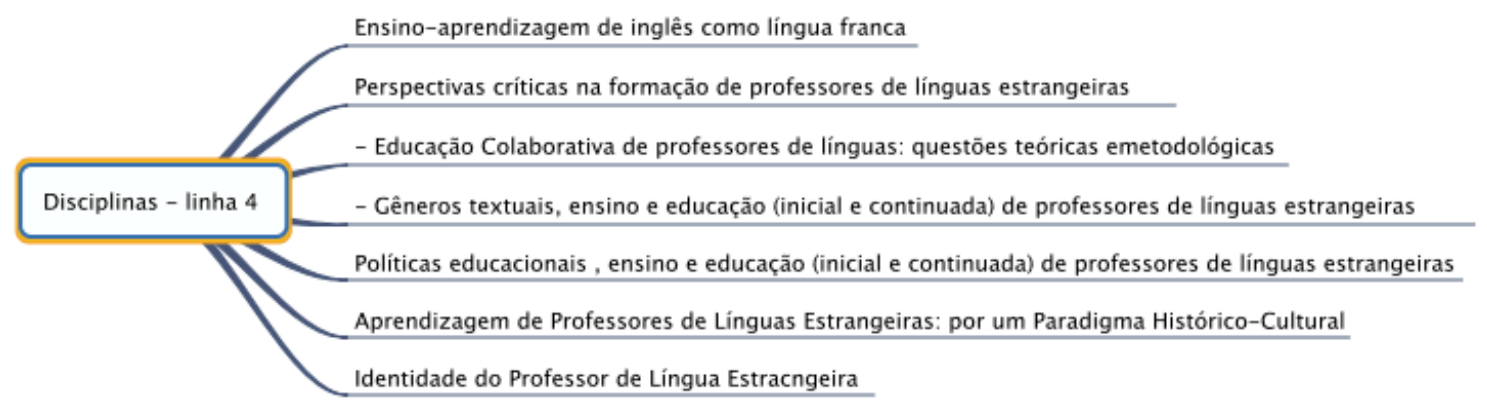

Fonte: elaborado pelos autores.

A questão ética está privilegiada em uma disciplina que pretende repensar as práticas discursivas. Seu propósito é oferecer uma visão das questões de ética nas pesquisas educacionais e, de modo particular, nas pesquisas em ensino-aprendizagem de línguas estrangeiras. A referência bibliográfica selecionada busca contemplar releituras contemporâneas de correntes teórico-filosófico-metodológicas que tomam o sujeito e a linguagem 
como um fenômeno histórico, cultural, social e ideológico. Ética, dialética, colaboração, métodos e práticas discursivas são discutidos através de textos de Maria A. Alba Celani, Marília Amorim, Suresh Canagarajah entre outros.

Com esta ótica, o projeto de pesquisa "Práticas sociais de (transform) ação de professores/as de Inglês um olhar sob as lentes da análise de discurso crítica", objetiva investigar ao longo das experiências de práticas de ensino (estágio), pelas lentes da análise do discurso crítica, redes de práticas sociais de transformação de professores de inglês com foco nas interações, representações e identificações produzidas.

Ainda, pretende-se identificar nas práticas nas quais professores em formação se envolvem em contexto de educação formal e analisar que potenciais constrangimentos são criados no processo de aprendizagem e desenvolvimento do docente.

Podemos concluir que a disciplina e o projeto de pesquisa priorizam e fazem da formação de professores objeto de estudo, análise no qual a teoria e prática juntas entram em campo para entender e aprimorar o processo de ensinar e aprender destes indivíduos em constituição profissional.

A disciplina que trata de políticas educacionais tem o objetivo de discutir este conceito, compreender as propostas governamentais para o ensino de língua estrangeira e a problemática de suas transposições didáticas na formação de professores. Para tanto, a referência bibliográfica se vale dos documentos oficiais e de nomes como Vilson José Leffa, Helena Costa Lopes Freitas, José Cardoso Palma Filho e Vera Lúcia Cristovão para pautar as discussões sobre formação de professores. Neste sentido, constrói-se um cenário crítico e bem argumentado sobre este assunto, o que pode levar o aluno a refletir sobre sua prática, sua identidade de professor.

Mais próximas da escola, as disciplinas de ensino e língua estrangeira na contemporaneidade e materiais didáticos e gêneros textuais buscam promover discussões sobre o ensino e aprendizagem de LE no contexto brasileiro e seus desafios no ambiente escolar. A referência bibliográfica propõe uma carga reflexiva a respeito da atuação do professor, levantando assuntos como a 
globalização, a hegemonia, imperialismo no ensino de LE (David Block, Suresh Canagarajah, David Crystal, Telma Gimenez); e a prática está mais evidenciada pela proposta de elaboração de atividades educativas, como avaliação e produção de materiais didáticos, que levem em conta aspectos das interrelações entre línguas estrangeiras, desenvolvimento econômico e cidadania. (Luiz Paulo da Moita Lopes, Anna Raquel Machado, Maria José Rodrigues Faria Coracini).

Nessa direção é que compartilhamos com Shulman (1986), o entendimento de que é necessário que o professor domine os conteúdos específicos de sua área, além de ter a clareza de como esses conteúdos transformam-se em objetos de ensino, seja pelos mecanismos de transposição didática, seja pela mediação, seja pelo conhecimento articulado dos saberes disciplinares e saberes curriculares.

Ainda nesse sentido, Moyses, Geraldi e Collares (2002) sugerem que a ideia de conhecimentos como objeto transmissível seja substituída pela ideia de conhecimento e saberes constituídos nos e pelos processos discursivos. Para tanto, afirma, no processo formativo de professores, que a ênfase essencial deveria centrar-se na questão da relação teoria e abordagem metodológica, o que em outras palavras significa discutir que teorias orientam tais ou quais práticas.

Como já dito, três disciplinas mencionam em seu título a formação de professores de língua estrangeira, as quais serão agora analisadas.

Modelos e Práticas Reflexivas na Formação de Professores de Línguas Estrangeiras apresenta em sua ementa o modelo reflexivo e pesquisas recentes sobre formação inicial e continuada de língua estrangeira. A referência bibliográfica extensa e organizada oferece textos potencialmente desafiadores (Telma Gimenez, Lynn Fendler, Donald Schon), textos críticos (Maria José Rodrigues Faria Coracini, Selma Garrido Pimenta, Fernanda Liberali), pesquisas sobre a abordagem reflexiva (Maria Helena Vieira Abrahão, Denise Ortenzi).

Propõe também um estudo sobre as comunidades de prática (Jean Lave, Arsène Wenger). Pela densidade dos assuntos e a extensão bibliográfica, esta 
disciplina espera que o participante não só conheça a abordagem reflexiva, mas dela se aproprie, a reinterprete diante das propostas de formação de professores sob a perspectiva sócio-histórico-cultural.

Aprendizagem de Professores de Línguas Estrangeiras: por um Paradigma Histórico-Cultural, tem o objetivo de oferecer uma ampla visão das teorias mediacionais da mente humana de interesse direto aos processos de aprendizagem e de desenvolvimento de professores de línguas estrangeiras. Aborda como conteúdo a formação de professores e a tradição históricocultural, sociohistórica e sociocultural. Estudos sobre a teoria da atividade (Newton Duarte1), comunidades de prática e colaboração (Yrjö Engeströn, Jean Lave, Kathrin $\mathrm{Au}$ ) tem $\mathrm{o}$ intuito de produzir conhecimento que permita argumentar sobre as implicações e os desafios práticos das teorias mediacionais de raiz sócio-histórico-cultural.

Identidade do Professor de Língua Estrangeira aborda a formação da identidade profissional do professor de língua estrangeira através de várias contribuições da pesquisa educacional e da Linguística Aplicada. Também, propõe como objetivo discutir ideias veiculadas em publicações seminais desta área a respeito do status do ensino, dos atrativos da profissão docente, de visões e formação de professores, de forças contextuais e pessoais que influenciam o desenvolvimento profissional docente. Autores como Diane Larsen-Freeman, Hilário Bohn, Denise Ortenzi, são utilizados para a constituição de um panorama que relaciona a identidade do profissional com o contexto social, as concepções de aprendizagem, as relações de trabalho, a política educacional, o conhecimento e as experiências profissionais.

Além das disciplinas, a área de língua estrangeira conta com um grupo de pesquisa intitulado "Formação de professores de língua estrangeira", que se caracteriza por pesquisas no campo de formação de professores de línguas, tanto na fase inicial como no desenvolvimento profissional continuado. Suas publicações compreendem as abordagens adotadas em programas específicos de formação, a avaliação de propostas metodológicas para o ensino de língua estrangeira (especialmente a de gêneros textuais), e a constituição de 
comunidades de aprendizagem no âmbito dos formadores de professores. Procura, ainda, articular seus estudos com atividades de ensino (graduação e pós-graduação), bem como de projetos de extensão. Deste modo, os resultados de suas pesquisas subsidiam diretamente as práticas dos participantes, com impacto imediato sobre as ações pedagógicas e investigativas.

As disciplinas explanadas até agora podem ser optativas, dependendo da linha a qual o estudante esteja vinculado. A única disciplina obrigatória ao mestrado, Metodologia de Pesquisa em Estudos da Linguagem, tem o objetivo de introduzir as principais correntes filosóficas e metodologias de pesquisa que servem às ciências humanas. Contribui para 0 aprimoramento ou reestruturação do projeto inicial de pesquisa dos ingressantes.

O grande desafio na formação do professor é formar docentes com perspectivas de sujeito inacabado, que se constrói a cada dia no exercício de sua função. A reflexão sobre sua prática, a busca por conhecimento, devem compor sua identidade durante toda sua carreira.

O PPGEL apresenta uma grade curricular diversificada que aborda principalmente questões do ensino e aprendizagem de línguas, o que acaba por perpassar pela formação de professores. Em língua estrangeira a oferta de disciplinas específicas para a formação de docentes é mais numerosa o que pode significar estar um pouco à frente de língua portuguesa, no que tange ao espaço para a discussão e reflexão deste tópico. A língua portuguesa, conta apenas com uma disciplina que trata especificamente da formação de professores, contudo os projetos de pesquisa ligados a linha debatem questões importantes sobre o tema. Também, como ocorre em língua estrangeira as outras disciplinas acabam por aproximar-se do assunto ao abordar o ensino e aprendizagem de língua materna.

Como já dito, Bakhtin e autores que discutem esta teoria, aparecem por diversas vezes na referência bibliográfica sugerida pelas disciplinas de língua portuguesa. Apesar de Bakhtin e seu círculo passarem a integrar as bases epistemológicas do campo de estudo da Linguística Aplicada, é importante ressaltar que suas contribuições são decorrentes de um trabalho de 
transposição didática, de inferências, de construções sobre a obra do autor, visto que o filósofo propõe conceitos e não metodologias para o ensino aprendizagem. Desta forma, abordar problemas linguísticos socialmente relevantes com a ótica da linguística é aceitar a língua como um artefato social.

De acordo com as referências selecionadas para o desenvolvimento das disciplinas constatamos que o estudo da língua portuguesa e estrangeira aponta para a formação reflexiva e crítica de professores. Esta formação tem a proposta de aguçar a inquietação deste sujeito que está inserido no campo educacional e que poderá buscar na teoria e na prática soluções para o dia a dia, para sua melhor atuação nas salas de aula, como professor pesquisador, não só da prática alheia, mas também aprimorando o seu próprio trabalho.

Sabemos que o trabalho do professor, seja ele formador ou professor em formação, é extremamente complexo, feito de escolhas, permeado de conflitos, envolvido em relações de poder, composto por diferentes visões de mundo, por diferentes formas de conhecimento que, sem dúvida, são fatores que podem gerar um estresse emocional bastante alto.

Com este trabalho demostramos algumas características da pósgraduação em Estudos da Linguagem da Universidade Estadual de Londrina e esperamos ter contribuído para o desenvolvimento das mesmas. Além disso, ter inspirado os professores de línguas a participar de uma pós-graduação para aprimorar seus conhecimentos e práticas e ampliar as discussões sobre o assunto.

\section{Referências}

AGUIAR, Denise Brasil Alavarenga. Formação de professores de língua portuguesa: impressões de viagem. Revista Querubim, Niterói, RJ, ano 8, set. 2012. Disponível em: <http://www.uff.br/feuffrevistaquerubim/images/ arquivos/artigos/formao_professores_de_lp_-_impresses_de_viagem-1.pdf >. Acesso em: 16 jan. 2014.

BAZERMAN, Charles. Gênero, agência e escrita. São Paulo: Cortez, 2006. 
BAZERMAN, Charles. The life of genre, the life in the classroom. In: BISHOP, W., OSTROM, H. (Org.). Genre and writing: issues, arguments, alternatives. Portsmouth: Heinemann, 1997. Parte II.

BRASIL. Ministério da Educação. Parecer CNE/CES 492/2001. Diretrizes Curriculares Nacionais dos cursos de Filosofia, História, Geografia, Serviço Social, Comunicação Social, Ciências Sociais, Letras, Biblioteconomia, Arquivologia e Museologia. Disponível em: <http://portal.mec.gov.br/cne/ arquivos/pdf/CES0492.pdf>. Acesso em: 20 jan. 2014.

DEWEY, John. Democracia e educação: capítulos essenciais. São Paulo: Ática, 2007.

DEWEY, John. The relation of theory to practice in education. In: NATIONAL SOCIETY FOR THE SCIENTIFIC STUDY OF EDUCATION, $3^{\text {th }}, 1904$, Bloomington. Yearbook... Bloomington: Public School Publishing Co., 1904. Part I, p. 140-169.

DINIZ-PEREIRA, Júlio Emílio. A prática como componente curricular na formação de professores. Educação, Santa Maria, v. 36, n. 2, p. 203-218, maio/ago. 2011

DOLZ, Joaquim; SCHNEUWLY, Bernand. Gêneros orais e escritos na escola. Campinas, SP: Mercado de Letras, 2004.

KLEIMAN, Angela. Os estudos de letramento e a formação do professor de língua materna. Revista Linguagem em (Dis)curso, Tubarão,v. 8, n. 3, set./dez. 2008.

LUZ, Mary Neiva Surdi da. Linguística e ensino: o discurso de entremeio na formação de professores de língua portuguesa. 2010, Tese (Doutorado em Letras) - Universidade Federal de Santa Maria, Santa Maria, RS, 2010.

MOYSES, Maria Aparecida Afonso; GERALDI, João Wanderley; COLLARES, Cecília Azevedo Lima. As aventuras do conhecer: da transmissão à interlocução. Educação \& Sociedade, Campinas, ano XXIII, n. 78, abr. 2002.

NÓvOA, António. Diz-me como ensinas e te dir-te-ei quem és e vice e versa. In: FAZENDA, I. A pesquisa em educação e as transformações do conhecimento. Campinas: Papirus, 1995. p. 29-40.

ORTH, Miguel Alfredo et al. Políticas educacionais: aspectos legais da educação básica. 3. ed. Canoas: Centro Universitário La Salle; Salles, 2007.

ORTH, Miguel Alfredo; Pauly, Evaldo Luis. História recente da formação de professores no Brasil: algumas ações instrumentais e estratégicas da política educacional. Roteiro, Videira, v. 36, n. 1, p. 147-166, jun. 2011. 
PIETRI, Émerson de. Concepções de língua e escola e proposta de ensino de língua portuguesa: discussões sobre reprodução / transformação social. Falla dos Pinhais, Espírito Santos de Pinhal, SP, v. 2, n. 2, jan./dez. 2005.

SÁNCHEZ GAMBOA, Silvio Ancisar. Fundamentos para la investigacion educativa: presupuestos epistemologicos que orientam al investigador. Santa Fé de Bogotá: Cooperativa, Editorial Magistério, 1998.

SAUSSURE, Ferdinand. Cours de linguistique générale. Paris: Payot \& Rivages, 1967.

SCHLINDWEIN, Luciane Maria; SOUZA E SOUZA, Maria Luiza de. A formação de professores na pós-graduação e educação em Santa Catarina: o que dizem as disciplinas. In: ENDIPE - ENCONTRO NACIONAL DE DIDÁTICA E PRÁTICAS DE ENSINO, 16., 2012, Campinas. Anais... Campinas: Junqueira \& Marin, 2012.

SHULMAN, Lee. Those who understand: knowledge growth in teaching. Educational Researcher, Washington, v. 15, n. 2, p. 4-14. Feb. 1986.

SILVA, Sandro Luís da. A leitura e sua avaliação na formação inicial do professor de Língua Portuguesa: contrastes e confrontos. Tese (Doutorado em Língua Portuguesa) - Pontifícia Universidade Católica de São Paulo, São Paulo, 2008.

TÁPIAS-OLIVEIRA, Eveline Mattos. Alguns conceitos Bakhtinianos e a mudança (esperada) na postura do professor. In: SEMINÁRIO DE PESQUISAS EM LINGÜÍSTICA APLICADA (SEPLA), 6., 2010, Taubaté. Anais... Taubaté: Universidade de Taubaté, 2010. p. 264-281. 